\title{
The Correlation Effect between Transportation and Economy in Beijing-Tianjin-Heibei area An analysis Based on PVAR Model
}

\author{
Wenli Wang ${ }^{1}$ \\ ${ }^{1}$ School of Economics and Management Beijing Jiaotong University Beijing, China
}

\begin{abstract}
Based on the annual panel data of Beijing-Tianjin-Hebei area from 1985 to 2018, this paper established a Panel Vector Autoregressive Model, variance decomposition, and impulse response function analyzing the linkage effect between the transportation and regional economy. The conclusions are as follows: Beijing-Tianjin-Hebei transportation integration and regional economic integration development are mutually reinforcing, but the results of variance decomposition show that they have different pulling forces, and the latter is more effectively than the former. The impulse response analysis show that the development of railways has made greater contributions to regional economic development than highways. In summary, there is a close relationship between the transportation integration and regional economic integration in the BeijingTianjin-Hebei region. They promote and coordinate with each other, but how to strengthen the relationship between them to make the area develop faster, more further research is needed.
\end{abstract}

\section{Introduction}

Regional economy refers to the complex formed by the interaction of internal economic conditions and external conditions in a certain area in a long-term social and economic activities due to geographical and economic factors. In 2014, the State Council proposed new requirements for the coordinated development of BeijingTianjin-Hebei, adding the preparation of the BeijingTianjin-Hebei regional plan to the "fast lane" to accelerate the integration of the capital economic circle including Beijing, Tianjin, and Hebei, Which makes it the third largest economic growth pole after the Yangtze River Delta and the Pearl River Delta. Beijing is where the capital is located and is the center of national political, economic and international cultural exchange. In the process of its integrated development, transportation network integration is the primary factor. Transportation is a hardware factor that hinders the coordinated development of regional integration, and also an important way for individuals to communicate with each other. In addition, transportation is the foundation and driving force of economic development, so studying the relationship between the integration of transportation networks and regional economic development has important practical guiding significance.

\section{Literature review}

The relationship between transportation and regional economy has always been a hot topic studied by scholars from all walks of life. The rapid development of society has increased the demand for transportation scale and quality. Regional economies at different levels of development have different needs for transportation. With the closer communication between regions, the mutual adaptation between transportation and regional economy is becoming more and more complicated. Scholars at home and abroad have studied the relationship between transportation and economic development extensively, which usually involves many aspects. However, it is undeniable that most scholars have pointed out that transportation can promote economic development, and in turn, economy can pull the development of transportation $^{[1]}$. There is a long-term equilibrium relationship between economic growth and transportation $^{[2]}$. Foreign scholars started to study the relationship between transportation and economic development earlier than China. As early as 1776, Adam Smith pointed out in the "Wealth of Nations " that the development of the transportation industry will help the growth of national wealth ${ }^{[3]}$. Matthew G. Kariaffis used DEA model, combined with cutting-edge theoretical methods, and took the United States case to study the coordination of transportation efficiency and transportation effects ${ }^{[4]}$.

Chinese scholars have also made some achievements in the research of transportation and economic development, mainly focusing on the following aspects: such Jiahuan Lv used data from Chongqing to study the relationship between transportation and economic development with the VAR model. He hold the view that there is a long-term co-integration relationship between transportation demand and economy. Economy drives the 
development of transportation industry, but the contribution rate of transportation industry to economy is smaller ${ }^{[5]}$. Zhengying Nie, on the basis of analyzing the interaction mechanism between transportation and economic system, constructed an evaluation index system. And she believes that although the coupling degree of the economy and transportation is lower, the overall improvement is steadily increasing, and the level of coupling coordination gradually changes from imbalance to coordination ${ }^{[5]}$. Jiahui Zhang evaluated the coordinated development of the transportation system and the economy by constructing an evaluation index system, using a combination of principal component analysis and regression analysis to evaluate the relationship between the two ${ }^{[7]}$. Xiang Jiao took two typical regions of BeijingTianjin-Hebei and Yangtze River Delta as the research objects. According to the panel data of the two regions and their sub-regions from 2009 to 2017 and the forecast data of 2020, a comprehensive evaluation index system was constructed by entropy method, which was used to calculate the development level of the coupling subsystem. Then, the coupling coordination degree between the two regions was measured by coupling model, and the coefficient of variation was used to verify the coupling coordination between Beijing-Tianjin-Hebei and Yangtze River Delta. It is considered that the coupling coordination degree of the two regions has been low, but both of them have shown a good trend of steady increase. The coupling coordination degree between the sub-regions of the two regions is significantly different, and the relative backwardness of transportation development level is still one of the main factors restricting the economic development of each sub-region ${ }^{[8]}$.

To sum up, the current research on the relationship between transportation integration and regional economic integration mainly conducted by static analysis methods, and there are few studies based on dynamic method analysis. From the existing research, it can be found that the coupling coordination degree in Beijing-Tianjin-Hebei region is low due to the relatively advanced development of Hebei's transportation. The development of transportation can bring positive effects to the regional economy and promote the balanced development of the regional economy, but its development level should also adapt to the development level of the regional economy and cannot be relatively advanced ${ }^{[8]}$. Therefore, on the basis of previous researches, this paper uses panel data from Beijing, Tianjin and Hebei to establish the PVAR model to analyze the relationship between the integration of regional transportation networks and regional economic development. Variance decomposition and impulse response function are used to further interpret.

\section{Data Source and Model Description}

\subsection{Data selection and processing}

Regional transportation integration refers to breaking geographical boundaries and administrative barriers in the region with the development of regional transportation planning as the goal. It is a very important basic condition to realize regional economic integration by considering the unified planning, management, organization and deployment of all transportation resources in the region from the perspective of comprehensive transportation system $^{[9]}$. This article mainly quantitatively analyze the network formed by external transportation hardware infrastructure. The five modes of transportation include: railways, highways, water transportation, civil aviation and pipelines, of which railways and highways contribute the most to the economic development of the study region. While water transportation, civil aviation and pipelines play a small role at this stage, so we only consider the contribution of railway and highway to the economic development of Beijing-Tianjin-Hebei region. With reference to the existing research, the indicators selected are as follows: the per capita GDP (pgdp / Yuan), railway cargo turnover ( $\mathrm{rtt} / 100$ million tons kilometers), highway cargo turnover ( $\mathrm{hft} / 100$ million tons kilometers), railway density (rd / km per square kilometer), and highway density (hd / km per square kilometer)). Among them the road density refers to the total mileage of roads per square kilometer. Road density is an important indicator of the development level of regional roads, and it is also an intuitive indicator to measure roads as an important infrastructure in social and economic development to meet traffic needs. Here we obtain the annual mileage of public railways divided by the area occupied by the region. All data are from the National Bureau of Statistics. In addition, in order to avoid the heteroscedasticity and data fluctuations, we take logarithmic processing on the obtained data, and the basic description of the new sequence obtained is as follows:

Table1. Descriptive statistical analysis of each variable

\begin{tabular}{|c|c|c|c|c|c|}
\hline Statistics & Inpgdp & Inrft & Inhft & Inrd & Inhd \\
\hline Mean & 9.6708 & 6.4527 & 5.2477 & -3.0870 & -0.4460 \\
\hline Median & 9.8281 & 6.2374 & 4.9946 & -2.9272 & -0.2626 \\
\hline Max & 11.8509 & 8.4830 & 9.0537 & -2.2825 & 0.3940 \\
\hline Min & 6.5779 & 5.2470 & 2.4350 & -4.0531 & -1.5408 \\
\hline S.E & 1.3869 & 0.9776 & 1.4838 & 0.5133 & 0.5975 \\
\hline
\end{tabular}

\subsection{The Description of PVAR Model}

The panel vector autoregressive (PVAR) model combines the advantages of the panel data model and the vector autoregressive model, which can take the variables we selected as endogenous variables and perform dynamic analysis to reflect the dynamic relationship between the variables. According to the selection criteria of the optimal lag order in Table 2, the PVAR (2) model is defined as follows:

$$
\begin{aligned}
& Y_{i, t}=\Gamma_{0}+\Gamma_{11}(L) Y_{i, t-1}+\Gamma_{22}(L) Y_{i, t-1}+\mu_{i t}, i=1,2,3 . t=1, \cdots, \mathrm{T} \\
& Y_{i, t}=\{\ln p g d p, \ln r f t, \ln r d, \ln h f t, \ln h d\}, \mathrm{i} \text { is the number of }
\end{aligned}
$$
selected provinces and cities, $t$ represents time, $\Gamma_{0}$ is the constant coefficient. 
Table2. VAR optimal lag order selection

\begin{tabular}{|c|c|c|c|c|c|c|}
\hline Lag & LogL & LR & FPE & AIC & SC & HQ \\
\hline 0 & 415.707 & NA & $\begin{array}{l}5.46 \mathrm{e}- \\
11\end{array}$ & -9.442 & $9.300 *$ & -9.385 \\
\hline 1 & 467.137 & 95.765 & $\begin{array}{l}2.98 \mathrm{e}- \\
11\end{array}$ & -10.049 & -9.199 & $\begin{array}{l}-707 * \\
9.7\end{array}$ \\
\hline 2 & 496.270 & $50.900 *$ & $\begin{array}{l}2.72 \mathrm{e}- \\
11^{*}\end{array}$ & $\begin{array}{l}-10.144 * \\
\end{array}$ & -8.585 & -9.516 \\
\hline 3 & 513.268 & 27.743 & $\begin{array}{l}3.32 \mathrm{e}- \\
11\end{array}$ & -9.960 & -7.693 & -9.047 \\
\hline 4 & 529.760 & 25.024 & $\begin{array}{l}4.15 \mathrm{e}- \\
11\end{array}$ & -9.765 & -6.789 & -8.566 \\
\hline
\end{tabular}

Note: * indicates the optimal lag order under this criterion, more indicators point to the second order, so choose the second order as the optimal lag order.

\section{Model Establishment and Estimation}

\subsection{Unit root test}

In order to avoid the "false regression" phenomenon, the panel data series must be tested for stationarity before regression $^{[10]}$. The results are shown in Table 3.

Table3. The results of unit test

\begin{tabular}{|c|c|c|c|c|c|c|}
\hline & Methods & Inpgdp & Inrft & Inrd & Inhft & Inhd \\
\hline \multirow{4}{*}{$\mathbf{L}$} & LLC & 1.351 & 0.919 & 0.900 & 1.733 & -0.193 \\
\hline & IPS & 2.164 & 2.235 & 2.430 & 2.629 & 1.730 \\
\hline & ADF & 0.618 & 0.691 & 1.397 & 0.459 & 1.027 \\
\hline & PP & 0.051 & 0.845 & 1.690 & $13.398 * *$ & 1.123 \\
\hline \multirow{4}{*}{ I(1) } & LLC & $-2.596 * * *$ & $-1.842 * *$ & $-6.061 * * *$ & 0.415 & $-5.608 * * *$ \\
\hline & IPS & $-2.165 * *$ & $-4.562 * * *$ & $-6.207 * * *$ & $-4.680 * * *$ & $-4.603 * * *$ \\
\hline & ADF & $14.453 * *$ & $31.623 * * *$ & $45.001 * * *$ & $32.624 * * *$ & $31.827 * * *$ \\
\hline & PP & $18.619 * * *$ & $57.468 * * *$ & $102.847 * * *$ & $62.727 * * *$ & $59.236 * * *$ \\
\hline
\end{tabular}

Note: L represents "level "; The number of * indicates the significance level, * indicates the $10 \%$ significance level, ** indicates the $5 \%$ significance level, and *** indicates the $1 \%$ significance level

\subsection{Estimation of PVAR}

We performed panel data VAR regression on the basis of the original model. The results are shown in Table 4, with Table4. the results of VAR estimation

\begin{tabular}{|c|c|c|c|c|c|}
\hline Variables & dlnpgdp & dlnrft & dlnrd & dlnhft & dlnhd \\
\hline \multirow{2}{*}{$\operatorname{dlnpgd}_{t-1}$} & 0.800608 & 0.412762 & 0.073092 & 0.284878 & -0.192965 \\
\hline & $(0.10489)$ & $(0.17502)$ & $(0.11013)$ & $(0.29591)$ & $(0.20600)$ \\
\hline \multirow{2}{*}{$\operatorname{dlnpgd}_{t-2}$} & 0.067592 & -0.347054 & 0.030694 & -0.137790 & 0.420255 \\
\hline & $(0.10549)$ & $(0.17602)$ & $(0.11076)$ & $(0.29760)$ & $(0.20717)$ \\
\hline \multirow{2}{*}{ dlnrftt-1 } & 0.103813 & 0.231524 & -0.024851 & 0.032428 & -0.029896 \\
\hline & $(0.06316)$ & $(0.10539)$ & $(0.06632)$ & $(0.17818)$ & $(0.12404)$ \\
\hline \multirow{2}{*}{ dlnrft $_{t-2}$} & 0.075236 & 0.010837 & 0.053230 & 0.019924 & 0.025546 \\
\hline & $(0.05080)$ & $(0.08476)$ & $(0.05333)$ & $(0.14330)$ & $(0.09976)$ \\
\hline \multirow{2}{*}{$\operatorname{dln} d_{t-1}$} & 0.079483 & -0.031587 & -0.235634 & 0.346189 & -0.123797 \\
\hline & $(0.09593)$ & $(0.16007)$ & $(0.10072)$ & $(0.27063)$ & $(0.18840)$ \\
\hline \multirow{2}{*}{$\operatorname{dln} d_{t-2}$} & 0.182305 & 0.331105 & 0.013292 & 0.208318 & -0.036693 \\
\hline & $(0.08622)$ & $(0.14387)$ & $(0.09053)$ & $(0.24324)$ & $(0.16934)$ \\
\hline \multirow{2}{*}{ dlnhft $_{t-1}$} & -0.047552 & -0.072176 & 0.045892 & 0.122053 & 0.122931 \\
\hline & $(0.03588)$ & $(0.05987)$ & $(0.03767)$ & $(0.10122)$ & $(0.07046)$ \\
\hline \multirow{2}{*}{ dlnhft $_{t-2}$} & 0.035525 & 0.046293 & 0.005802 & 0.064486 & -0.016322 \\
\hline & $(0.03103)$ & $(0.05177)$ & $(0.03258)$ & $(0.08753)$ & $(0.06093)$ \\
\hline \multirow{2}{*}{$\operatorname{dlnh}_{t-1}$} & 0.048790 & 0.321816 & -0.153898 & -0.024042 & 0.033858 \\
\hline & $(0.05476)$ & $(0.09138)$ & $(0.05750)$ & $(0.15449)$ & $(0.10755)$ \\
\hline \multirow{2}{*}{$\operatorname{dlnh}_{t-2}$} & 0.003768 & -0.088526 & 0.240360 & 0.688199 & 0.024758 \\
\hline & $(0.05928)$ & $(0.09892)$ & $(0.06224)$ & $(0.16724)$ & $(0.11642)$ \\
\hline
\end{tabular}

Note: The numbers in brackets is standard error

It can be seen from the AR root diagram of the lag structure test of the VAR model in Fig. 1 that the reciprocal modulus of all the characteristic roots of the VAR model is less than 1, all falling within the unit circle, indicating that the established VAR model is stable.

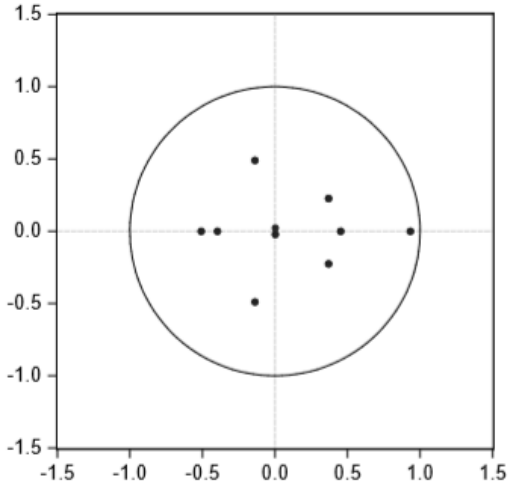

Fig 1. AR root diagram of VAR model lag structure test 


\subsection{Impulse Response Function}

The impulse response function describes the impact of adding a standard shock to the current value and future value of the endogenous variable on the disturbance item. The impact on a variable directly affects this variable and is transmitted to other through the dynamic structure of VAR All endogenous variables. Fig.

2 shows a positive impact on the regional economic development, and the corresponding response made by the integration of the transportation network during the 10 period. Fig. 3 shows the corresponding response to the regional economic development.

After applying a positive shock to dlnrft, dlnpgdp made a positive response in the first two periods, and then stabilized; after applying a positive shock to dlnrd, dlnpgdp showed a positive response in the first three periods.,the response tends to be stable afterwards; after applying a positive shock to dlnhft, dlnpgdp has a negative response in the previous periods and then the impact of fluctuations near 0 has almost disappeared; while after applying a positive shock to dlnhd, there was an obvious fluctuation and then it became stable. From this we can conclude that the development of railways has made a greater contribution to regional economic development than the roads during the integration of transportation networks.
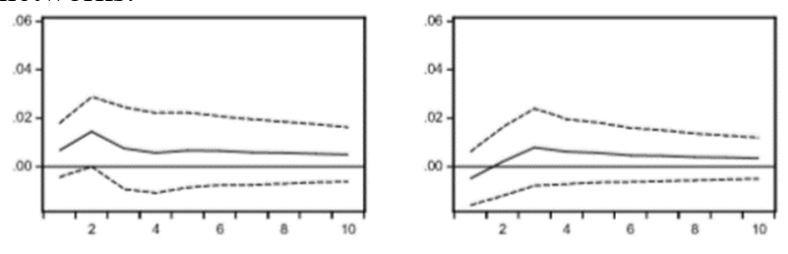

2. the response of dinggdp to dinrt
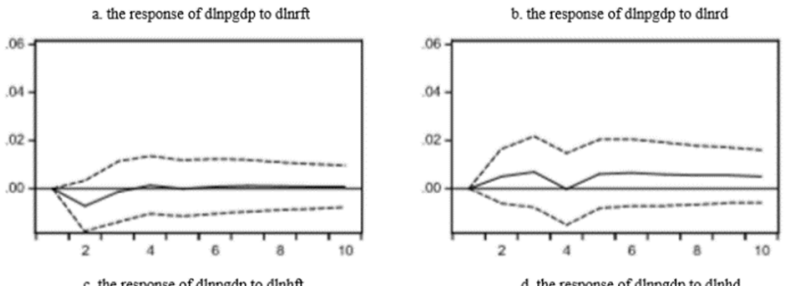

c. the response of dilnggdp to dinhtt

d. the response of dlinpgdp to dlinhd

Fig 2. Impulse response diagram of regional economic development

Similarly, from Fig. 3 we can conclude that when a positive impact is given to the indicator of GDP per capita representing regional economic development, various measures that measure the integration of transportation networks have fluctuated to a certain extent in previous periods, and then tends to a stable positive value, which shows that regional economic development has a significant promotion effect on the integration of transportation networks, and provides a powerful guarantee for the realization of transportation network integration, to a certain extent, promote the development of transportation integration.
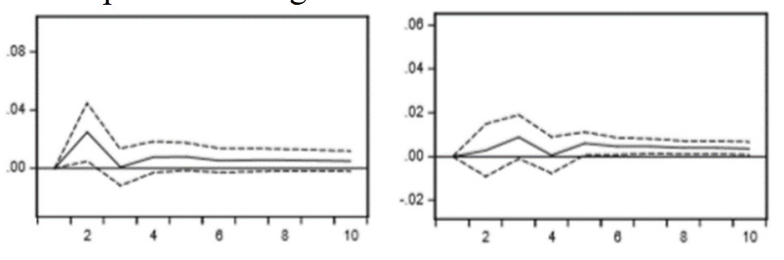

a. the response of dinrt to dinpgdp

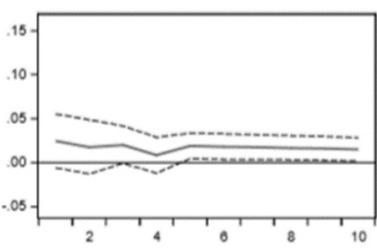

b. the response of dinrd to dlinggdp

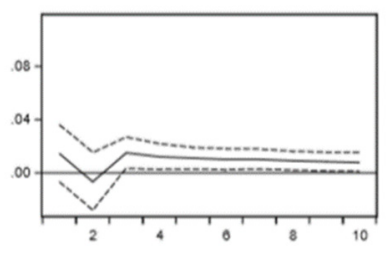

c. the response of dinht to dlnpgdp

d. the response of dinhd to dinggdp

Fig 3. Impulse response diagram of transportation network

\subsection{Variance Decomposition}

Variance decomposition provides another way to describe the dynamic changes of the system. The impulse response function is to track the impact of the system on an endogenous variable, while the variance decomposition is to decompose the predicted mean square error of the system into the contribution of the various variables in the system. The results of the variance decomposition are shown in the table5, which shows that: the lowest explanatory power of the integration of the transportation network for regional economic growth is the road freight turnover, the explanatory power is only $0.470 \%$, and the highest is the railway freight turnover, The interpretive power is $4.188 \%$; on the contrary, the lowest explanatory power of the regional economic growth on the integration to the transportation network is also the road freight turnover, the explanatory power is $2.274 \%$, and the highest is the railway freight turnover of $7.678 \%$, which is significantly higher than the transportation network. This suggests that the degree of mutual influence between the integration of transportation networks and regional economic growth is unequal.

Table5. The results of variance decomposition

\begin{tabular}{|c|c|c|c|c|c|c|}
\hline Variables & Periods & dInpgdp & dlnrft & dInrd & dInhft & dInhd \\
\hline dlnpgdp & 10 & 91.41846 & 4.188143 & 1.849660 & 0.469712 & 2.074027 \\
\hline dlnrft & 10 & 7.677773 & 76.99660 & 2.266510 & 1.988179 & 11.07094 \\
\hline dlnrd & 10 & 2.826698 & 70.17532 & 4.202700 & 2.205705 & 20.58958 \\
\hline dlnhft & 10 & 2.273744 & 3.758131 & 9.846779 & 67.85428 & 16.26707 \\
\hline dlnhd & 10 & 2.692376 & 0.871390 & 9.134226 & 2.984992 & 84.31702 \\
\hline
\end{tabular}

\section{Conclusion and Recommendations}

\subsection{Conclusion}

Based on the above analysis, the degree of mutual promotion between transportation network integration and regional economic development is unequal, which shows that the regional economic growth has a significantly greater effect on the integrated transportation network than the latter on the former. 
At the same time, the results of impulse response analysis show that after a positive impact is imposed on the variables of the integration of the transportation network, the speed and degree of the railway's response is significantly better than that of the highway, which suggests that railway contributes more to regional economic development than highways.

In summary, there is a close relationship between the integration of the transportation network in the BeijingTianjin-Hebei region and the economic integration in the region. The two promote and coordinate with each other. However, how to make better use of existing resource to strengthen the linkage effect between the two to promote better and faster regional development still needs further research.

\section{2 suggestions}

There is a mutual influence and mutual restriction between transportation and regional economy. The development of transportation industry should adapt to the economic development, it needs a rational plan to construct the transportation, from which we can improve the utilization rate of various transportation modes. The role of the transportation industry is not only to meet the transportation needs of passengers and reduce transportation costs, but also to reduce the total operating cost of the national economic system so as to improve the overall operating efficiency of the national economic system from the perspective of the whole social and economic development. Therefore, in the planning of transportation, we should fully take the economic and social development status and current organizational status within the region into account, so that we can improve the reasonable configuration of spatial distribution and structure of transportation in the region.

In the future construction in the process of integration in this area, the government should pay more attention to the railway construction, and attaches great importance to the lag effect of railway on the regional economy. Additionally, we should pull the construction of regional rail transit network system to a higher speed, and form the main railway-intercity railway-suburban railway and the metro rail transit network system efficiently. Strengthening the coordination of highway-railwayaviation and other transportation ways, promoting the rational allocation of resources and making full use of the capacity of all modes of transport can help us further promote regional economic development.

\section{Acknowledgment}

I would like to express my sincere gratitude to my tutor, professor. Ou, who gave me great help by providing me with necessary materials, inspiration of new ideas and advice of great value. Secondly, I pleased to acknowledge my classmates for their invaluable assistant. Finally, I'd like to express my great gratitude to my parents for their support, which is of great help for me to finish this thesis. Thanks to all those who helped me during the writing of my thesis.

\section{References}

1. Liangjun Zhang. Study on the Coordinated Development of Transportation and Regional Economy [J]. Traffic World,2019(27):16-17.

2. Rong Ren, Lianyuan Cheng, Zhuoran Xie, Gang Zong Dynamic Effect Analysis of Transportation Infrastructure Investment and Economic Growth - An Empirical Study Based on VAR Model [J]. Research on Science and Technology Management, 2012,32(04):85-89.

3. Adam Smith. research on the cause and nature of national wealth $[\mathrm{M}]$. Wuhan: Zhongnan University of Finance and Economics Press, 2003

4. Matthew G Karlaftis. A DEA approach for evaluating the efficiency and effectiveness of urban transit systems[J]. European Journal of Operational Research,2004,152(2).

5. Jiahuan Lv, Wenqiang Fan. Empirical analysis of the relationship between regional transportation demand and GDP based on VAR model [J]. transportation technology and economy, 2016,18(02):52-55+61.

6. Zhengying Nie Ping Li. Beijing-Tianjin-Hebei Transportation Integration and Regional Economic Coupling: Coordination Analysis Based on Entropy Weight Method [J]. Comprehensive Transportation, 2019,41(04):37-42.

7. Jiahui Zhang.Study on the Coordination between Integrated Transportation System and Economy [J]. modern business trade industry, 2017(09):13-14.

8. Xiang Jiao. Study on Coupling of Transportation and Regional Economy [D]. Beijing Jiaotong University, 2019.

9. Yi Lu, Huazhong Li, Wei Peng. Framework of regional transportation integration planning and integration model $[\mathrm{J}]$. Integrated Transportation, 2010(10):43-49.

10. Richard D.F. Harris, Elias Tzavalis. Inference for unit roots in dynamic panels where the time dimension is fixed[J]. Journal of Econometrics,1999,91(2). 